\title{
The Microstructure and Oxidation Resistance of Aluminide MeCrAIY-Modified Coatings Obtained by Slurry Method on Rene 80 Superalloy
}

\author{
Marek Goral \\ Research and Development Laboratory for Aerospace Materials, Rzeszow University of Technology, \\ Rzeszow, Poland \\ Email: mgoral@prz.edu.pl
}

Received April 16, 2012; revised May 31, 2012; accepted June 20, 2012

\begin{abstract}
The slurry method is one of the oldest techniques of deposition of aluminide coating on the nickel superalloy, titanium alloys and steel. It is characterized by relatively low costs of its realisation and necessary equipment. This method enables a simple modification of chemical composition of the coating through addition of different powders. The author showed study on the possibility of modification of the Al-Si slurry chemical composition used for aluminide coating deposition by addition of MeCrAlY powder. The slurry was deposited by immersion than the diffusion treatment at $950^{\circ} \mathrm{C}$ for two hours was applied. The thickness of obtained coatings was in the range of $30-65 \mu \mathrm{m}$.
\end{abstract}

Keywords: Slurry Method; Aluminide Coatings; Nickel Superalloy

\section{Introduction}

The diffusion aluminide coatings are used for protection of the turbine blades made from nickel superalloys and used as elements of aircraft and industrial gas turbines, against oxidizing influence of exhaust gases [1]. The most common technique used for aluminizing is the pack cementation method. It involves putting the elements in metal container and covering them with a powder which contains an active powder (source of aluminium), neutral filler material as well as halide activator. The process is performed in protective atmosphere of argon, in the chamber furnace [2]. The gas methods (out of pack, gas phase aluminizing) are currently used in the aerospace industry. The blades are located in those methods over the powder or granules containing aluminum. The aluminum fluoride is most commonly used as an activating agent. The aluminizing is conducted in retort furnace in the temperature of $900^{\circ} \mathrm{C}-1050^{\circ} \mathrm{C}$ and the argon and hydrogen protective atmosphere for $2-6$ hours $[3,4]$. The most modern method of obtaining aluminide coatings is the chemical vapour deposition (CVD method). The halogenide $\mathrm{Al}$ activator (aluminium chloride) is created in CVD process - as opposed to other methods - during chemical reaction between $\mathrm{HCl}$ and aluminum granules, in the external heated generator. The generated gas is introduced to the retort, where the coated elements are placed. The further development of diffusion aluminizing methods is focused on the modification of aluminide coatings by other elements-zirconium, hafnium, palladium, platinum and silicon $[5,6]$. The slurry method has been used, among other described methods, for a couple of decades. It involves the deposition of organic or nonorganic slurry, which contains the aluminum powder, on the blades surface, followed by the drying process. The aluminide coatings are formed as a result of a diffusion heat treatment process, in the atmosphere of argon, hydrogen or in vacuum. The slurry method is used for preparation of coatings on the turbine blades. It enables to create the aluminide coating on the surface of regenerated blade. It is possible to modify the chemical composition of the slurry by adding the powders with different chemical composition mainly by silicon. Praxair company is one of the companies which manufactures this kind of slurry (J. Sermaloy) [7]. The requirements concerning the usage of chromium compounds, due to their carcinogenic properties, led to development of new kinds of slurries, based on organic binders. Product manufactured by Ceral company-LSR SIALOY is an example of this kind of slurry [8]. The slurry method enabled the production of high temperature resistant coatings on different materials. This technique is used to obtain, except the nickel superalloys, the diffusion coatings on the cast steel or intermetallic $\gamma$-TiAl alloys $[9,10]$. The conducted till now research on modifying the diffusion aluminide coating obtained with slurry method, by addition of Me- 
CrAlY to commercial slurry containing aluminum and silicon powders [11]. The authors present the techniques of obtaining the annealed coatings in a reductive hydrogen atmosphere (instead of argon used so far) involving the modification of components ratio.

\section{Experiments}

The process of aluminide coating deposition was performed on the Rene 80 nickel superalloy. Its chemical composition is presented in Table 1. The cylinder-shaped samples, with a diameter of $14 \mathrm{~mm}$, were sandblasted and washed. The MeCrAlY powder was obtained from the typical AMDRY 995C powder used for plasma spraying during the milling process. The chemical composition of powder is presented in Table 1. After the milling process, the final grain size in the MeCrAlY powder was approx. $20 \mu \mathrm{m}$. The samples were coated by immersion in the slurry. Addition of the MeCrAlY powder into a typical commercial slurry Ceral 10 were done in 1:2 ratio. The drying process was conducted for $24 \mathrm{~h}$ in the temperature of $80^{\circ} \mathrm{C}$. The diffusion heat treatment process was conducted in the retort furnace for 2 hours into hydrogen atmosphere condition (flow $2 \mathrm{l} / \mathrm{min}$ ) and in the temperature of $950^{\circ} \mathrm{C}$. The last stage of coating deposition process was sandblasting and washing to remove the slurry residue.

The microstructure analysis was conducted with a use of the Hitachi S-3400 scanning electron microscope connected with chemical composition microprobe analysis (EDS) manufactured by Thermo company.

The cyclic oxidation test was performed in chamber furnace in static laboratory air in the temperature $1100^{\circ} \mathrm{C}$.
The 23-hour heating cycles were used. The mass measurements were conducted on the analytical balance, with accuracy of the order $10^{-4} \mathrm{~g}$. The moment of mass decrease below the initial mass is considered to be a resistance criterion.

\section{Results}

The microstructure analysis of obtained coatings confirmed a presence of many cracks. The thickness of coating was influenced by addition of MeCrAlY powder. In case of slurry obtained from Al-Si, the thickness was approx. $65 \mu \mathrm{m}$. With an increase of MeCrAlY powder content, there was a decrease of coating thickness. In the case of adding the MeCrAlY powder into Al-Si slurry with the 1:2 ratio, the coating thickness was approx. 34 $\mu \mathrm{m}$.

\subsection{The Microstructural Analysis}

Three zones could be observed (Figure 1) in a structure of the coating obtained from the commercial Al-Si slurry. The thickness of the outer zone presented on Figure 1(a) (Zone 1) was of approx. $5 \mu \mathrm{m}$. The chemical composition analysis, confirmed presence of 44 at $\%$ of silicon and 34 at $\%$ of chromium in this point. Moreover, the titanium, molybdenum and nickel in the amount of 4 - 5 at $\%$ were also present in this area. In the lower Zone 2 with a thickenss of approx. $55 \mu \mathrm{m}$ many precipitates with the high silicon content (Figure 1(a), Table 2 pt 2) were observed. Those precipitates were located uniformly in the whole area of Zone 2 (Figure 1(b), Table 2 pt 4). The precipitate matrix (Figure 1(a), Table 2 pt 5) contained

Table 1. The nominal chemical composition of Rene 80 alloy [wt \%].

\begin{tabular}{ccccccccccc}
\hline Material & Ni & Co & Cr & W & Mo & Al & Ti & Zr & C & Y \\
\hline Rene 80 & Bal. & 9.5 & 14 & 4 & 4 & 3 & 5 & 0.06 & 0.17 & - \\
MeCrAlY AMDRY 995C powder & Bal. & 38.5 & 21 & - & - & 8 & - & - & - & 0.5 \\
\hline
\end{tabular}

Table 2. The results of chemical composition analysis in areas presented on Figure 1.

\begin{tabular}{|c|c|c|c|c|c|c|c|c|}
\hline \multirow{2}{*}{ Point } & \multicolumn{8}{|c|}{ Element at\% } \\
\hline & Al & Si & $\mathbf{T i}$ & Cr & Co & $\mathbf{N i}$ & Mo & $\mathbf{W}$ \\
\hline 1 & 6.04 & 44.13 & 4.79 & 34.13 & - & 1.43 & 5.32 & 4.16 \\
\hline 2 & 40.89 & 13.47 & 1.26 & 3.86 & 5.08 & 34.60 & 0.50 & 0.33 \\
\hline 3 & 42.30 & 10.32 & 1.10 & 3.29 & 5.39 & 36.33 & 0.55 & 0.73 \\
\hline 4 & 28.96 & 11.13 & 1.17 & 28.53 & 3.06 & 23.24 & 1.89 & 2.01 \\
\hline 5 & 47.22 & 0.25 & 0.72 & 2.76 & 4.84 & 43.48 & 0.43 & 0.30 \\
\hline 6 & 20.82 & - & 11.10 & 27.76 & 6.64 & 26.72 & 3.27 & 3.70 \\
\hline 7 & 11.31 & - & 10.83 & 6.69 & 6.27 & 62.30 & 1.24 & 1.36 \\
\hline
\end{tabular}




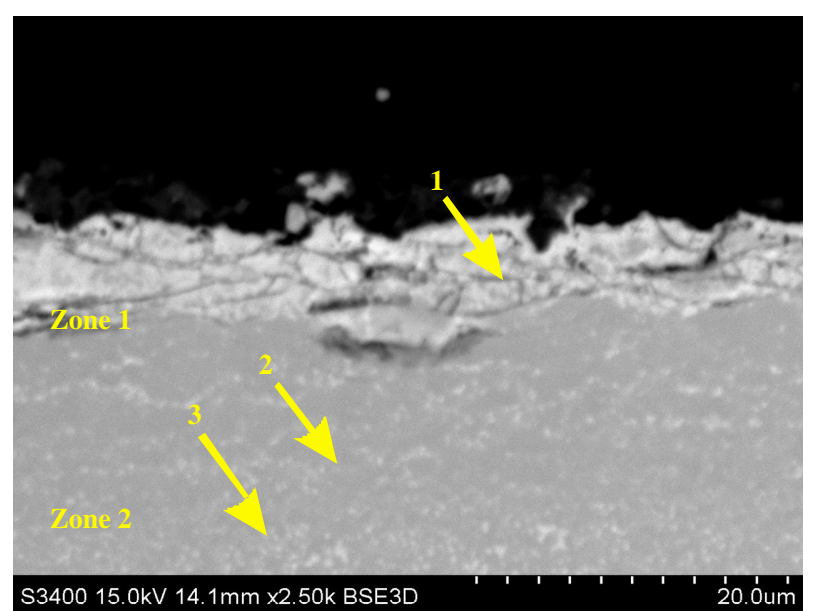

(a)

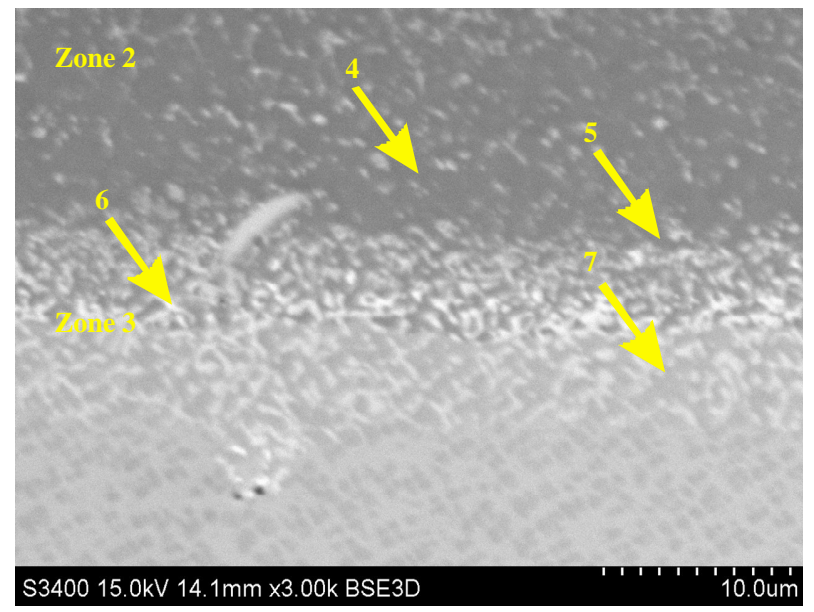

(b)

Figure 1. Microstructure of the coating obtained on the Rene 80 superalloy from a slurry contained $100 \mathrm{wt} \%$ of Al-Si powder. The coating was obtained during diffusion heat treatment at $950^{\circ} \mathrm{C} / 2 \mathrm{~h}$ under hydrogen atmosphere condition with marked points of chemical composition microanalysis.

approx. 47 at $\%$ of aluminum, 43 at $\%$ of nickel, approx. 5 at $\% \mathrm{Co}$ as well as 3 at $\%$ of $\mathrm{Cr}$. Presence of $\mathrm{Ti}, \mathrm{Si}, \mathrm{Mo}$ (with a concentration $<1$ at $\%$ ) was also confirmed. In the inner zone (marked as Zone 3 on Figure 1(b) pt 6,7) the existence of silicon was not observed. In the 6th point (Figure 1(b), Table 2) the aluminum concentration was approx. 20 at $\%$. For chromium and nickel it was approx. $27 \mathrm{at} \%$.

In the interface zone, between inner Zone 2 and base material (Figure 1(b), Table 2 pt 7), the concentration of aluminum was approx. 11 at $\%$, and for nickel -62 at $\%$. The titanium content in this area was approx. 10 at $\%$. For chromium and cobalt it was approx. 6 at $\%$.

The coating obtained form the slurry which contains the addition of MeCrAlY powder were characterized by a lack of outer zone rich in silicon and chromium. Its smaller thickness was also observed. Two basic zones were observed in theirs structure (Figure 2). The layers with 33\% (mass) content of MeCrAlY powder had precipitates in its outer zone (marked as " 1 " on Figures 2 and 3) and in the inner zone with the thickness of approx. $5 \mu \mathrm{m}$ (marked as " 2 " on Figure 2). The chemical composition analysis conducted for precipitates in the outer zone (marked as " 1 ") of a coating formed form the slurry with an addition of $33 \%$ (mass) of NiCrAlY powder revealed a presence of the silicon (approx. 19 at $\%$ ) and chromium (approx. 45 at $\%$, Figure 2(a) pt 1, Table 3). In the analyzed area, the aluminum content was approx. 19 at $\%$ and approx. 12 at $\%$ for nickel. The analysis of the basis in the outer zone " 1 " of the coating (Figure 2(a) pt 2, Table 3) revealed a high aluminum content-approx. 52 at $\%$ and 37 at $\%$ for nickel. The chemical composition

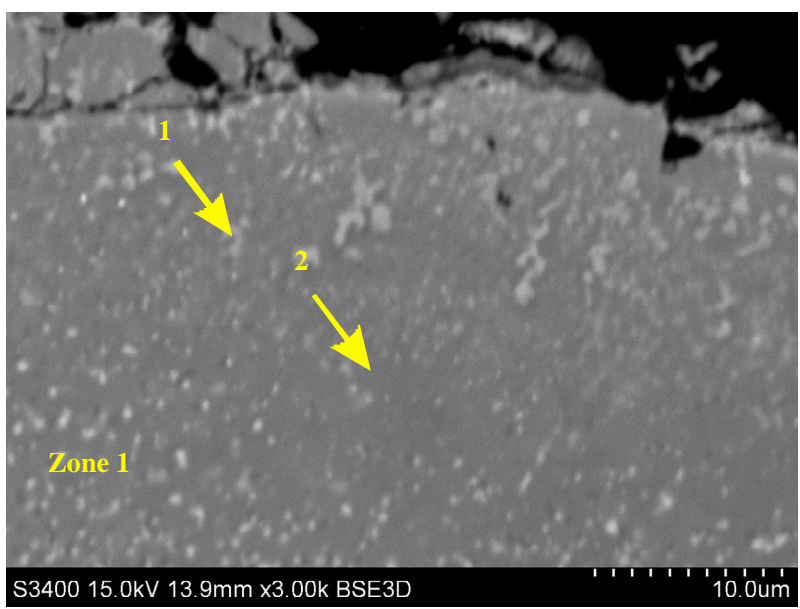

(a)

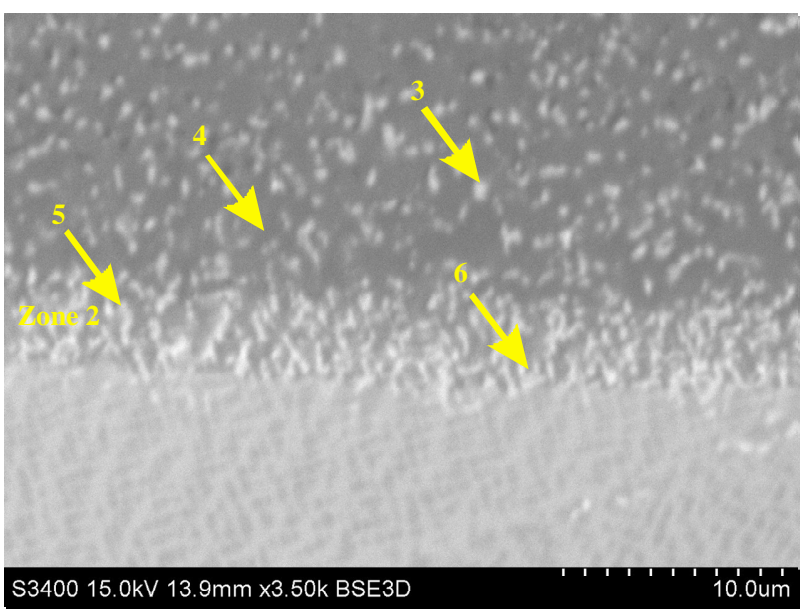

(b)

Figure 2. Microstructure of the coating obtained on Rene 80 superalloy from slurry contained $66 \mathrm{wt} \% \mathrm{Al}-\mathrm{Si}$ and $33 \mathrm{wt} \%$ of NiCrAlY powder. The coating was created during diffusion heat treatment at $950^{\circ} \mathrm{C} / 2 \mathrm{~h}$ under hydrogen atmosphere condition with marked points of chemical composition microanalysis. 
analysis conducted in the area of the inner Zone 2 (Figure 2(b) pt 3, 4, Table 3 ) showed a aluminum concentration of 44 - 51 at $\%$. The precipitate matrix in this area was characterized by nickel content of approx. $40 \mathrm{at} \%$ (pt 4 on Figure 2(b), Table 3) as well as by the existence of chromium and cobalt. In the inner zone (Figure 2(b) pt 5 and 6) the aluminum content was approx. $13.6-14.88$ at $\%$. Moreover, the chemical composition analysis by EDS method, revealed a high chromium amount (34 - 45 at $\%$ ) and a presence of titanium, molybdenum and tungsten.

\subsection{Results of Oxidation Test}

The results of mass change measurement during cyclic oxidation is presented on Figure 3. Tests performed in the temperature of $1100^{\circ} \mathrm{C}$ revealed the increase of corrosion resistance of the Rene 80 alloy with deposited aluminide layers. The mass of the sample without the protective coating dropped below the initial mass after the 4th cycle. The samples with the protecting coating increased above the initial mass after the 4th cycle. There were no mass change observed for the samples covered with commercial Ceral slurry as well as the for those modified with the multicomponent MeCrAlY powder.

\section{Discussion}

In the article authors presented new method of chemical composition modification of the aluminide coatings obtained by slurry method. The conducted research showed a possibility of introduction of the conventional Al-Si

Table 3. The results of chemical composition analysis in areas presented on Figure 2.

\begin{tabular}{|c|c|c|c|c|c|c|c|c|c|}
\hline \multirow{2}{*}{ Point } & \multicolumn{9}{|c|}{ Element at\% } \\
\hline & Al & Si & $\mathbf{T i}$ & $\mathrm{Cr}$ & Co & $\mathrm{Ni}$ & $\mathbf{N b}$ & Mo & $\mathbf{W}$ \\
\hline 1 & 52.08 & 1.60 & 0.83 & 3.09 & 5.28 & 37.12 & - & - & - \\
\hline 2 & 19.42 & 19.34 & 1.85 & 44.55 & 2.06 & 11.54 & 0.04 & 1.20 & - \\
\hline 3 & 44.41 & - & 6.49 & 19.11 & 3.78 & 19.06 & - & 3.07 & 4.08 \\
\hline 4 & 51.46 & - & 0.87 & 2.52 & 5.52 & 39.64 & - & - & - \\
\hline 5 & 14.88 & - & 7.67 & 45.18 & 4.92 & 17.67 & - & 5.22 & 4.46 \\
\hline 6 & 13.60 & - & 8.85 & 33.85 & 7.69 & 26.88 & - & 4.87 & 4.26 \\
\hline
\end{tabular}

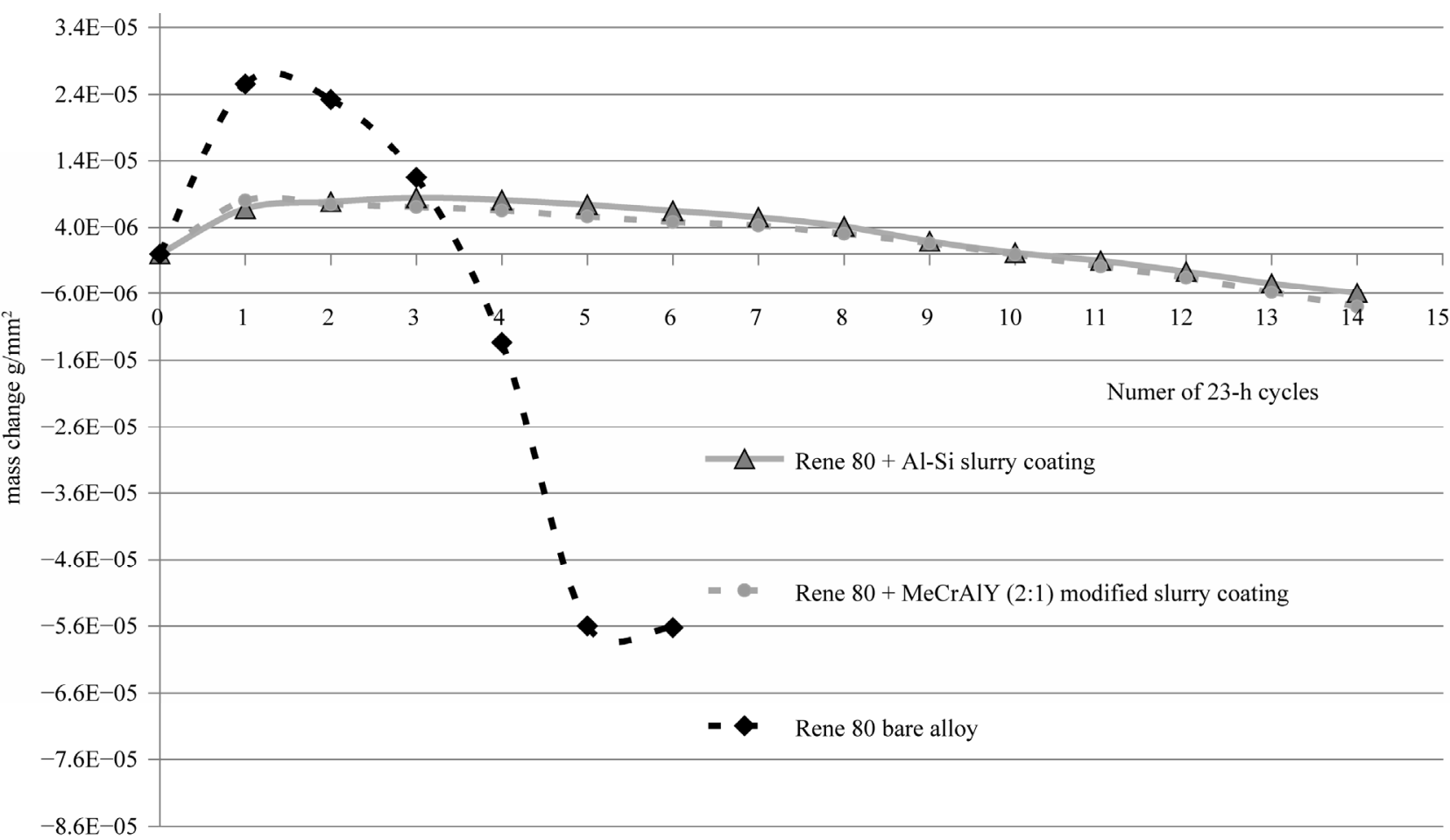

Figure 3. The results of mass change measurement during the cyclic oxidation process in the temperature of $1100^{\circ} \mathrm{C}$. 
slurry consisting of multicomponent MeCrAlY alloy. However, one has met some difficulties resulting from a high density of introduced MeCrAlY powder. One has observed the sedimentation of heavier powder components on the bottom of the vessel during the application process. All obtained coatings were characterized by a structure, which is typical for highly active process and was created during the inward diffusion of aluminium. After the diffusion heat treatment process one has also observed a presence of many fractures in the coating resulting from internal stresses. It could be caused by a short time of diffusion annealing process ( $2 \mathrm{~h}$ ), fast cooling and using of hydrogen atmosphere, instead of argon atmosphere used till now. It caused in the coatings with the addition of NiCoCrAlY powder fractures and exfoliation of the outer layer with high content of silicon and chromium. In the structure of all obtained aluminide coatings, a few characteristic zones can be observed. In the layer obtained form a commercial slurry containing only aluminum and silicon powders, the outer zone was rich in silicon and chromium, which could be a proof of silicide formation. In all layers, one observed the zone with fine porous precipitates with the diameter less than $1 \mu \mathrm{m}$. They contained silicon on the basis of the $\beta$-NiAl intermetallic phase, with 50 at $\%$ of aluminum. In all layers, the inner zone with a thickness of approx. $5 \mu \mathrm{m}$ was observed. The result of cyclic oxidation tests showed an increase of oxidation resistance of samples with aluminide layers. The research did not proved a significant difference in oxidation resistance between layer made from commercial Al-Si slurry and layer modified with MeCrAlY powder. It was caused by the observed sedimentation process of the powder. One observed no influence of the additional outer layer with high silicon and chromium content, on the increase of oxidation resistance of the layer created from the commercial $\mathrm{Al}-\mathrm{Si}$ slurry. The presented results indicate the significant difficulties in obtaining the aluminide coatings modified by powders, which are made of metals being components of MeCrAlY alloy and have higher density. It is necessary to prepare a new binder, which ensures the possibility of homogenization of the slurry and prevents the sedimentation process. Searching for new methods of obtaining thermal barrier coatings is a significant reason for continuing the research. The European Project "Particoat" is a good example of it.

\section{REFERENCES}

[1] Y. Tamarin, "Protective Coatings for Turbine Blades," ASM International, Almere, 2002

[2] Z. D. Xiang, J. S. Burnell-Gray and P. K. Datta, "Aluminide Coating Formation on Nickel-Base Superalloys by Pack Cementation Process," Journal of Materials Science, Vol. 36, No. 23, 2001, pp. 5673-5682. doi:10.1023/A:1012534220165

[3] A. Squillace, R. Bonetti, N. J. Archer and J. A. Yeatman, "The Control of the Composition and Structure of Aluminide Layers Formed by Vapour Aluminising," Surface and Coatings Technology, Vol. 120-121, 1999, pp. 118123. doi:10.1016/S0257-8972(99)00347-3

[4] J. A. Haynes, M. J. Lance, B. A. Pint and I. G. Wright, "Characterization of Commercial EB-PVD TBC Systems with CVD (Ni,Pt)Al Bond Coatings," Surface \& Coatings Technology, Vol. 146-147, 2001, pp. 140-146. doi:10.1016/S0257-8972(01)01483-9

[5] M. J. Li, X. F. Sun, H. R. Guan, X. Jiang and Z. Q. Hu, "Effects of Palladium Incorporation on the Oxidation Behavior at High Temperature," Oxidation of Metals, Vol. 59, No. 5-6, 2003, pp. 483-502.

[6] J. Angenete and K. Stiller, "Comparison of Inward and Outward Grown Pt Modified Aluminide Diffusion Coatings on a Ni Based Single Crystal Superalloy," Surface and Coatings Technology, Vol. 150, No. 2-3, 2002, pp. 107-118. doi:10.1016/S0257-8972(01)01544-4

[7] T. Kircher, B. G. McMordie and S. Shankar, "Slurry Compositions for Diffusion Coatings," US Patent, No. 6444 054, 2000.

[8] Information Materials from Ceral USA Company. http://www.ceralusa.com

[9] M. Góral and L. Swadźba, "Modification of Aluminide Coatings by Slurry Method on Ni-Superalloys," Corrosion Protection, Vol. 4-5, 2007, pp. 120-123.

[10] A. Haynes, B. L. Armstrong, S. Dryepondt and Y. Zhang, "Oxidation Behavior of Slurry Aluminide Coatings on Stainless Steel Alloy CF8C-Plus," Proceedings of ICMCTF Conference, San Diego, 2-6 May 2011.

[11] M. Goral, L. Swadzba, G. Moskal, M. Hetmanczyk and T. Tetsui, "Si-Modified Aluminide Coatings Deposited on Ti46Al7Nb Alloy by Slurry Method," Intermetallics, Vol. 17, No. 11, 2009, pp. 965-967. doi:10.1016/j.intermet.2009.04.006 